\title{
Body's image concerns and its impact on academic achievements
}

\begin{abstract}
Introduction: Someone's self-perception is somebody's very own mental representation or identity or as organized definitive learning about one's self that could manage the social conduct. Young people observed to be occupied with redesigning and figuring their mental self-image. Poor self-perception diminishes self-adequacy and self-regard which cause mutilation in scholarly accomplishment.
\end{abstract}

Method: An observational study was led utilizing online questionnaire, 160 college undergraduates from various health sciences disciplines were included including both male, and female subjects. Effect of mental self-perception on educational accomplishments was examined.

Results: Results revealed that, physical appearance or body image did affect academic achievement or scholastic accomplishment. Most of the undergraduate students showed concerns regarding self-image, they get distressed due to physical appearance, further, their physical appearance also interfere in getting education and performing daily tasks. It is also observed that students who are satisfied with their self-image obtained higher grades as compare to their counterparts. Students found to be involve in watching TV as well as reading beauty magazine which also influence their cognitive powers and hence change their self-regard.

Conclusion: Understanding of connections between a positive self-perception and academic achievement can influence programs that are offered at college and universities. This study could be useful to academic wellbeing instructors, faculty and student affairs professionals involved in students counseling and motivations. Further research is needed to explore the link between academic success and lack of society`s concern regarding idea about beauty in reality.
Volume 7 Issue 3 - 2017

Tallat N, Fatima A, Fiza K, Adiya D

Sindh Medical College, Jinnah Sindh Medical University, Pakistan

Correspondence: Tallat Naz, Physiology Instructor, Department of Physiology, Sindh Medical College, Jinnah Sindh Medical University, Karachi, Pakistan, Tel 009-234-638I4724, Email tallant.naz@jsmu.edu.pk

Received: February 20, 2016 | Published: February 16, 2017

\section{Introduction}

An individual's feeling of self-worth can be associated with body shape or image. ${ }^{1}$ Self-perception is the mental picture we have of the size, shape and form of our own bodies and additionally of our sentiments about these characteristics and the parts that constitute our bodies. ${ }^{2}$ For some students, college is a conundrum between the genuine way of scholarly interest and the draw to fit in with societal desires. These desires can be effective powers as they characterize themselves mentally and physically. This journey for presents numerous issues, especially to adjust with regularly misshaped perspectives of beauty and self-image. ${ }^{3}$ It is characterized as the way a man sees or think about his body and how it looks to others. ${ }^{4}$ Self-perception is somebody's very own mental representation or is organized explanatory knowledge about one's self that could control the social conduct. Self-image is the way in which we consider our own physical, mental and emotional attributes, the measurement of our ego and social position. Correct self-observation is critical to think about attitudinal capacities and individual behavioral learning. ${ }^{5}$ Teenage period is an ideal opportunity to organizing one's self perspective which is determinant for psychological, emotional and physical advancement. Self-image energizes their feeling of qualities to gain behavioral wellbeing and separation. Self-image with respect to physical appearance turns out to be more noticeable during teenage years. ${ }^{6}$ University students found to have vital worries about self-perception about body image perceptions because they want to achieve or maintain a healthy weight and appearance. ${ }^{7}$ This is due to business advertisers who utilize physical body perception to sell their products. ${ }^{8}$ Sponsors particularly target young people, which expand their awareness of body image. Thus, teenagers' selfperceptions impact their practices. Underprivileged self-perception may bring down self-appraisals, thus negatively influencing academic achievements. ${ }^{9,10}$ In any case, little is thought about how students are influenced by the self-image. Accordingly, this study is intended to look at either self-perception influences scholastic accomplishment.

\section{Methodology}

The present study was conducted at Jinnah Sindh Medical University, Karachi, Pakistan in collaboration with the Institute of Health \& Business Management, JSMU, Karachi. This is an observational and analytical correlation study type. University students of various health sciences discipline were included with age group 18-30 years. A structured questionnaire was use and filled online. Data was analyzed by using SPSS version 16, and represented as Mean \pm SD as well as Frequencies and Percentages.

\section{Results}

\section{Baseline characteristics}

Table 1 showed the baseline data. There were total 160 participants in this study and out of this 44 were male and 116 were females. Mean age was $19.97 \pm 2.3$ years, mean BMI was $22.07 \pm 5.4$, Average GPA of students was $3.0 \pm 0.4$. Average Education was $12.21 \pm 0.9$. The duration of watching TV/day was $3.0 \pm 5.6$ and time spent on social media or internet was average about $4.3 \pm 6.4$. 


\section{Impact of self image or physical appearance}

Association between grades obtained and distress caused by physical appearance: Table 2 showed that those who score higher grad achievers have no distress due to physical appearance where as those who score average grades showed to have mild, moderate or severe levels of distress due to their physical image.

\section{Appearance}

Association between grades obtained and concern about appearance of any unattractive part of body: Table 3 showed that those who score higher grades showed $50 \%$ have no concern whereas $50 \%$ were concern about unattacrtive parts of body. Those who score B, B- and C grades found to be more concerned about their unattractive body parts.

Association between grades obtained and interference of physical appearance in getting education: Table 4 display values that showed relationship between grades obtained and interference due to appearance in their education career. Those who obtained A and A+ grade, $50 \%$ of them showed no effect whereas $50 \%$ showed moderate interference in getting education due to any physical appearance whereas those who get lower grades showed lesser interference of physical appearance in getting education.

Association between grades obtained and depression due to physical appearance: Table 5 showed that higher graders get never depressed due to their physical appearance whereas those who get other grades have high frequency of depression due to their appearance.

Association between grades obtained and BMI: Table 6 showed high graders are overweight whereas other graders are mostly healthy weight.

Association between grades obtained and influence of media: Table 7 showed that high achiever student spent only one hour on watching TV whereas other grade achievers spend more time with TV.

Table I Descriptive Statistics

\begin{tabular}{lll}
\hline Gender & Male (n) & $\mathbf{4 4}$ \\
\hline $\mathbf{N}=\mathbf{1 6 0}$ & Female (n) & $\mathbf{I ~} \mathbf{6}$ \\
\hline & & Mean + Std. Deviation \\
\hline Age & $19.97+2.3$ \\
Year of Education & $12.21+0.9$ \\
BMI & $22.07+5.4$ \\
GPA/Percentage & $3.0+0.4$ \\
No. Hours watch TV/Day & $3.0+5.6$ \\
No. Hours Internet use/Social Media/Day & $4.3+6.4$ \\
\hline
\end{tabular}

Table 2 Association between Grades Obtained and Distress Caused By Physical

\begin{tabular}{lllll}
\hline \multicolumn{7}{l}{ How much Distress is Caused by your Physical Appearance? } \\
\hline & No Distress & Mild and not too Disturbing & Moderate and Disturbing, but Manageable & Severe and Very Disturbing \\
\hline A and A+ & $2(100.0 \%)$ & $0(.0 \%)$ & $0(.0 \%)$ & $0(.0 \%)$ \\
A- & $3(60.0 \%)$ & $2(40.0 \%)$ & $0(.0 \%)$ & $0(.0 \%)$ \\
B & $39(55.7 \%)$ & $21(30.0 \%)$ & $6(8.6 \%)$ & $4(5.7 \%)$ \\
B+ & $11(45.8 \%)$ & $10(41.7 \%)$ & $3(12.5 \%)$ & $0(.0 \%)$ \\
B- & $12(44.4 \%)$ & $7(25.9 \%)$ & $6(22.2 \%)$ & $2(7.4 \%)$ \\
C & $11(47.8 \%)$ & $4(17.4 \%)$ & $7(30.4 \%)$ & $1(4.3 \%)$ \\
\hline
\end{tabular}

Table 3 Association between Grades Obtained and concerned about appearance of any unattractive part of body

\begin{tabular}{|c|c|c|c|c|c|}
\hline & \multicolumn{5}{|c|}{ Are you Concerned about Appearance of any part of Body which you Consider Unattractive? } \\
\hline & Not at all Concerned & Somewhat concerned & Moderately Concerned & Very Concerned & Extremely Concerned \\
\hline $\mathrm{A}$ and $\mathrm{A}+$ & $I(50.0 \%)$ & $0(.0 \%)$ & $0(.0 \%)$ & $\mathrm{I}(50.0 \%)$ & $0(.0 \%)$ \\
\hline A- & $2(40.0 \%)$ & $2(40.0 \%)$ & $0(0.0 \%)$ & $0(0.0 \%)$ & $I(20.0 \%)$ \\
\hline B & $20(28.6 \%)$ & $23(32.9 \%)$ & $20(28.6 \%)$ & $4(5.7 \%)$ & $3(4.3 \%)$ \\
\hline B+ & $10(41.7 \%)$ & $7(29.2 \%)$ & $3(12.5 \%)$ & $3(\mid 2.5 \%)$ & $\mathrm{I}(4.2 \%)$ \\
\hline B- & $4(\mid 4.8 \%)$ & $\mathrm{II}(40.7 \%)$ & $5(18.5 \%)$ & $5(\mid 8.5 \%)$ & $2(7.4 \%)$ \\
\hline C & $8(34.8 \%)$ & $8(34.8 \%)$ & $2(8.7 \%)$ & $4(17.4 \%)$ & $\mathrm{I}(4.3 \%)$ \\
\hline C- & I(I4.3\%) & $5(71.4 \%)$ & I(I4.3\%) & $0(.0 \%)$ & $0(.0 \%)$ \\
\hline
\end{tabular}

Table 4 Association between Grades Obtained and interference of physical appearance in getting education

\begin{tabular}{lllll}
\hline \multicolumn{5}{c}{ How much Interference is cause by your Physical Appearance, with your Education or Ability to Function? } \\
\hline & Never & Occasionally & Moderately Often & Often \\
\hline A and A+ & $\mathrm{I}(50.0 \%)$ & $0(.0 \%)$ & $\mathrm{I}(50.0 \%)$ & $0(.0 \%)$ \\
A- & $4(80.0 \%)$ & $\mathrm{I}(20.0 \%)$ & $0(0.0 \%)$ & $0(0.0 \%)$ \\
B & $48(69.6 \%)$ & $\mathrm{II}(15.9 \%)$ & $6(8.7 \%)$ & $4(5.8 \%)$ \\
B+ & $18(75.0 \%)$ & $4(16.7 \%)$ & $0(0.0 \%)$ & $1(4.2 \%)$ \\
B- & $18(66.7 \%)$ & $5(18.5 \%)$ & $2(7.4 \%)$ & $2(7.4 \%)$ \\
\hline
\end{tabular}


Table Continued..

\begin{tabular}{lllll}
\hline & \multicolumn{4}{l}{ How much Interference is cause by your Physical Appearance, with your Education or Ability to Function? } \\
\hline & Never & Occasionally & Moderately Often & Often \\
\hline C & $\mathrm{I} 7(73.9 \%)$ & $5(21.7 \%)$ & $\mathrm{I}(4.3 \%)$ & $0(.0 \%)$ \\
C- & $4(57.1 \%)$ & $\mathrm{I}(14.3 \%)$ & $\mathrm{I}(\mathrm{I} 4.3 \%)$ & $\mathrm{I}(\mathrm{I} 4.3 \%)$ \\
\hline
\end{tabular}

Table 5 Association between Grades obtained and depression due to physical appearance

\begin{tabular}{lll}
\hline & \multicolumn{2}{l}{ Do you get Depressed/Sad/Angry about your Appearance? } \\
\hline Grades & Yes & No \\
A and A+ & $0(0 \%)$ & $2(100 \%)$ \\
A- & $2(40 \%)$ & $3(60 \%)$ \\
B & $19(27.5)$ & $48(69.6)$ \\
B+ & $5(20.8 \%)$ & $18(75.0)$ \\
B- & $11(40.7 \%)$ & $16(59.3 \%)$ \\
C & $7(30.4 \%)$ & $15(65.2 \%)$ \\
C- & $1(14.3 \%)$ & $5(71.4 \%)$ \\
\hline
\end{tabular}

Table 6 Association between Grades obtained and BMI of subjects

\begin{tabular}{|c|c|c|c|c|c|c|c|}
\hline & $A$ and $A+$ & A- & B & B+ & B- & C & C- \\
\hline Healthy Weight & $0(0 \%)$ & $\mathrm{I}(20 \%)$ & $31(44 \%)$ & II (46\%) & $16(59 \%)$ & $7(30 \%)$ & $3(43 \%)$ \\
\hline Morbidly Obese & $0(0 \%)$ & $0(0 \%)$ & $\mathrm{I}(\mathrm{I} .4 \%)$ & $0(0 \%)$ & $0(0 \%)$ & $0(0 \%)$ & $0(0 \%)$ \\
\hline Obese & $0(0 \%)$ & $\mathrm{I}(20 \%)$ & $2(2.8 \%)$ & $0(0 \%)$ & $0(0 \%)$ & $2(8.7 \%)$ & $0(0 \%)$ \\
\hline Over Weight & $2(100 \%)$ & $2(40 \%)$ & $10(14 \%)$ & $3(12.5 \%)$ & $4(14.8 \%)$ & $6(26 \%)$ & $3(43 \%)$ \\
\hline Severly Obese & $0(0 \%)$ & $0(0 \%)$ & $5(7 \%)$ & $0(0 \%)$ & $0(0 \%)$ & $\mathrm{I}(4.3 \%)$ & $\mathrm{I}(\mathrm{I} 4.3 \%)$ \\
\hline Under Weight & $0(0 \%)$ & $\mathrm{I}(20 \%)$ & $22(31 \%)$ & $10(42 \%)$ & $7(26 \%)$ & $7(30 \%)$ & $0(0 \%)$ \\
\hline
\end{tabular}

Table 7 Association between Grades obtained and influence of Media

\begin{tabular}{lllllll}
\hline \multicolumn{7}{c}{ How many hours you watch TV/movies every day? } \\
\hline A and A+ & $\mathbf{0}$ & $\mathbf{I}$ & $\mathbf{2}$ & $\mathbf{3}$ & $\mathbf{4}$ & $\mathbf{7}$ \\
A- & $0 \%$ & $100 \%$ & $0 \%$ & $0 \%$ & $0 \%$ & $0 \%$ \\
B & $1.40 \%$ & $51 \%$ & $36 \%$ & $0 \%$ & $0 \%$ & $20 \%$ \\
B+ & $0 \%$ & $25 \%$ & $46 \%$ & $10 \%$ & $1.40 \%$ & $0 \%$ \\
B- & $0 \%$ & $41 \%$ & $44.40 \%$ & $7.40 \%$ & $0 \%$ & $4.20 \%$ \\
C & $0 \%$ & $70 \%$ & $22 \%$ & $9 \%$ & $0 \%$ & $7.40 \%$ \\
C- & $0 \%$ & $43 \%$ & $29 \%$ & $14.30 \%$ & $14.30 \%$ & $0 \%$ \\
\hline
\end{tabular}

\section{Discussion}

Academic achievement is an important determinant of a good job opportunities, desired earnings, high class social circle and social life and good lifestyle maintenance. Many factors influence the academic performance; self-image is one of the important factors. Importance of perception of self- image in educational process is highlighted by many educationists. When the person is satisfied, he will be happier, confident, motivated, and will have right attitude to succeed. Many studies from western countries showed association between physical appearance and academic results. This study revisited this important topic by collecting the data from students of different health sciences disciplines from Karachi, Pakistan.

Present study showed that most students were concerned with their physical appearance, but high grade achievers showed lesser influence and distress due their body image as compare to lower grade achievers. However, data also showed some students have no concerned with their physical appearance still they get lower grades. Rosenblum had studied the body dis-satisfaction by measuring physical attractiveness, and body mass index in teenagers. Study revealed that over adolescence, girls showed increased, while boys decreased body dissatisfaction. ${ }^{11}$
Present study showed that the high graders are overweight as compare to healthy weight but lower graders. In our study there were only 2 students who are high achiever whereas other grade holders are more in numbers so there is a need to collect data with large number of students. Also, our data showed that high achievers have no effect of physical appearance, so the overweight in our population is not a hindrance for motivated career oriented students.

Our results are comparative with other studies. Literature revealed that overweight and obesity induce psychosocial influences, such as stigmatization from teachers and peers, low self-esteem, higher rates of anxiety disorders, depression and other psychopathologies, ${ }^{12,13}$ which in turn responsible to lower the academic achievement of adolescents. ${ }^{14} \mathrm{~A}$ study conducted in Thailand by Mo-Suwan et al have depicted that overweight students' grades showed lower GPA than their healthy-weight peers. ${ }^{15}$ Pakistani students might be goal oriented rather than influenced by self-perception taken from media. In present study the average students fall in healthy and average weight category but still they score lower because of poor self-perception. So when students are overweight and dissatisfied with body appearance, they try to lose weight, ${ }^{16}$ they may try hard to reach their ideal weight. Although they may successfully become healthy weight person, but in the meantime, the time spent on losing weight may be likely to result in poor exam performance. 
Media has great influence on self-image of students. Present study showed that high graders spent less time on watching TV and therefore has less influence on their own physical appearance and academic results. Whereas average students found more involve in watching TV and hence, have greater influence of media. The literature suggests that body image perceptions and concerns are important for university students, probably because of the increasing popularity of achieving or maintaining a healthy weight and appearance..$^{17,18}$

\section{Acknowledgments}

None.

\section{Conflicts of interest}

Author declares there are no conflicts of interest.

\section{Funding}

None.

\section{References}

1. Fairburn CG, Beglin SJ. Assessment of eating disorders: Interview or self-report questionnaire? Int J Eat Dis. 1994;16(4):363-370.

2. Slade PD. Body image in anorexia nervosa. Br J Psychiatry Suppl. 1988;2:20-22.

3. Bergstrom RL, Neighbors C. Body image disturbance and the social norms approach: An integrative review of the literature. Journal of Social and Clinical Psychology . 2006;25(9):975-1000.

4. Khor GL, Zalilah MS, Phan YY, et al. Perceptions of body image among Malaysian male and female adolescents. Singapore Med J. 2009;50(3):303-311.

5. Băban A. Educational counseling, a methodological guide for counseling classes, Psinet Publishing house, Cluj-Napoca, Balkans. 2001. p. 66.
6. Fung MSC, Yuen M. Body image and eating attitudes among adolescent Chinese girls in Hong Kong. Percept Mot Skills. 2003;96(1):57-66.

7. Yahia N, El-Ghazale H, Achkar A, et al. Dieting practices and body image perception among Lebanese university students. Asia Pac J Clin Nutr. 2011;20(1):21-28.

8. Thompson KJ, Heinberg LJ. The media's influence on body image disturbance and eating disorders: We've reviled them, now can we rehabilitate them? Journal of Social Issues. 1999;55(2):339-353.

9. Page RM, Lee CM, Miao NF. Self-perception of body weight among high school students in Taipei, Taiwan. Int J Adolesc Med Health. 2005; 17(2):123-136.

10. Chen LJ, Fox KR, Haase AM. Body shape dissatisfaction and obesity among Taiwanese adolescents. Asia Pac JClin Nutr. 2008;17(3):457-460.

11. Rosenblum GD, Lewis M. The relations among body image, physical attractiveness, and a body mass in adolescence. Child Dev. 1999;70(1):50-64.

12. Needham BL, Crosnoe R. Overweight status and depressive symptoms during adolescence. J Adolesc Health. 2005;36(1):48-55.

13. Puhl RM, Heuer CA. The stigma of obesity: a review and update. Obesity. 2009;17(5):941-964.

14. Diego MA, Field TM, Sanders CE. Academic performance, popularity, and depression predict adolescent substance use. Adolescence. 2003;38(149):35-42.

15. Mo-Suwan L, Lebel L, Puetpaiboon A, et al. School performance and weight status of children and young adolescents in a transitional society in Thailand. Int J Obes Relat MetabDisord. 1999;23(3):272-277.

16. Crow S, Eisenberg ME, Story M, et al. Psychosocial and behavioral correlates of dieting among overweight and non-overweight adolescents. $J$ Adolesc Health. 2006;38(5):569-574.

17. Yahia N, El-Ghazale H, Achkar A, et al. Dieting practices and body image perception among Lebanese university students. Asia Pac J Clin Nutr. 2011;20(1):21-28. 